\title{
Combined Hot Air and Microwave-Vacuum Drying of Cranberries: Effects of Pretreatments and Pulsed Vacuum Osmotic Dehydration on Drying Kinetics and Physicochemical Properties
}

\author{
Zi-Liang Liu ${ }^{1}$ - Izabela Staniszewska ${ }^{2} \cdot$ Danuta Zielinska $^{3} \cdot$ Yu-Hao Zhou ${ }^{1} \cdot$ Konrad W. Nowak $^{2} \cdot$ Hong-Wei Xiao $^{1}$. \\ Zhongli Pan $^{4} \cdot$ Magdalena Zielinska ${ }^{2}$ (D)
}

Received: 19 December 2019 / Accepted: 23 July 2020 / Published online: 30 July 2020

(C) The Author(s) 2020

\begin{abstract}
The aim of the study was to evaluate the effect of sonication (S), microwave-vacuum (MWV), convective freezing (F), cryogenic freezing $(\mathrm{N})$, and their combinations, as well as pulsed vacuum osmotic dehydration (PVOD) on the drying kinetics, bioactive compounds, texture and color of whole cranberries during combined hot air convective drying, and microwave-vacuum drying (HACD+MWVD). Drying of berries took from 20 to 493 min. Drying rate was enhanced by $23 \%$ and drying time of nonosmotically dehydrated fruits was shortened by $33 \%$ using F treatment, while MWV decreased moisture content before drying by $68 \%$ and shortened the drying time of PVOD berries by $96 \%$. Generally, total phenolic (TP) content increased during processing, total flavonoids (TF), and total monomeric anthocyanins (TMA) contents decreased, while the values of ferric reducing antioxidant power (FRAP) of dried fruits depended on the initial pretreatment. F and HACD+MWVD yielded fruits of the highest $L^{*}$ (33.8 \pm 0.7$), a^{*}(25.2 \pm 1.0)$, and $b^{*}(7.3 \pm 0.6)$, inflated oval shape, and a small amount of wrinkles on the surface. PVOD and HACD+MWVD resulted in flat and wrinkled fruits.
\end{abstract}

Keywords Cranberries $\cdot$ Ultrasound $\cdot$ Microwave-vacuum treatment $\cdot$ Freezing $\cdot$ Hybrid drying $\cdot$ Quality attributes

\begin{tabular}{|c|c|c|}
\hline \multicolumn{3}{|c|}{ Abbreviations } \\
\hline \multicolumn{2}{|c|}{$\mathrm{C}$} & control (raw non-treated) \\
\hline \multicolumn{2}{|l|}{$\mathbf{S}$} & sonication \\
\hline \multicolumn{2}{|c|}{ MWV } & microwave-vacuum treatment \\
\hline \multicolumn{2}{|c|}{$\mathbf{N}$} & cryogenic freezing \\
\hline \multicolumn{2}{|l|}{$\mathbf{F}$} & convective freezing \\
\hline \multicolumn{2}{|c|}{$\mathrm{S}+\mathrm{F}$} & sonication and convective freezing \\
\hline \multicolumn{2}{|c|}{$\mathrm{MWV}+\mathrm{F}$} & $\begin{array}{l}\text { microwave-vacuum treatment and con- } \\
\text { vective freezing }\end{array}$ \\
\hline \multicolumn{2}{|c|}{ PVOD } & pulsed vacuum osmotic dehydration \\
\hline \multicolumn{3}{|c|}{$\begin{array}{l}\triangle \quad \text { Magdalena Zielinska } \\
\text { m.zielinska@uwm.edu.pl }\end{array}$} \\
\hline 1 & \multicolumn{2}{|c|}{$\begin{array}{l}\text { College of Engineering, China Agricultural University, } \\
\text { Beijing, China }\end{array}$} \\
\hline 2 & $\begin{array}{l}\text { Departme } \\
\text { Mazury i }\end{array}$ & $\begin{array}{l}\text { ystems Engineering, University of Warmia and } \\
\text { yn, Heweliusza 14, 10-718 Olsztyn, Poland }\end{array}$ \\
\hline 3 & $\begin{array}{l}\text { Departm } \\
\text { Olsztyn, }\end{array}$ & $\begin{array}{l}\text { hemistry, University of Warmia and Mazury in } \\
\text { Poland }\end{array}$ \\
\hline 4 & Departme & ological and Agricultural Engineering, University \\
\hline
\end{tabular}

HACD+MWVD hot air convective drying and microwavevacuum drying total polyphenols, mg GAE/g DM total flavonoids, mg CAE/g DM total monomeric anthocyanins, mg $\mathrm{Cy}-$ 3G/g DM

FRAP ferric reducing antioxidant power, mg TE/ g DM

MR moisture ratio

$\mathrm{DR}_{\mathrm{AVG}} \quad$ average drying rate, $\mathrm{kg} \mathrm{H}_{2} \mathrm{O} / \mathrm{kg} \mathrm{DM} / \mathrm{min}$ $t \quad$ drying time, $\min$ $\mathrm{MC}_{(t)} \quad$ moisture content of fruits at any level and $\mathrm{MC}_{\mathrm{e}}$ $\mathrm{MC}_{0}$ any time, dry basis $(\mathrm{db})$ equilibrium moisture content $(\mathrm{db})$ the initial moisture content of the material (db)

\section{Introduction}

Cranberries (Vaccinium macrocarpon) contain high level of bioactive compounds, which poses health-promoting 
Table 1 Parameters of initial treatments before convective and microwave-vacuum drying (HACD+MWVD) of cranberries

Initial treatment and dehydration
Sonication
$\mathrm{S}$
Sonication+convective freezing
$\mathrm{S}+\mathrm{F}$
$\mathrm{S}+\mathrm{F}$

Microwave-vacuum pretreatment MWV

Microwave-vacuum pretreatment + convective freezing MWV $+\mathrm{F}$

\section{Convective freezing $\mathrm{F}$}

Cryogenic freezing

$\mathrm{N}$

Pulsed vacuum osmotic dehydration PVOD
Parameters

Ultrasounds frequency: $25 \pm 5 \mathrm{kHz}$; ultrasonic power input: $600 \mathrm{~W}$; time: $10 \mathrm{~min}$; mode: $1 \mathrm{~s}$ impulse and $1 \mathrm{~s}$ gap between impulses; medium: distilled water; volume of medium: $1 \mathrm{dm}^{3}$; sample mass: $0.2 \mathrm{~kg}$.

Ultrasounds frequency: $25 \pm 5 \mathrm{kHz}$; ultrasonic power input: $600 \mathrm{~W}$; time: $10 \mathrm{~min}$; mode: $1 \mathrm{~s}$ impulse and $1 \mathrm{~s}$ gap between impulses; medium: distilled water; volume of medium: $1 \mathrm{dm}^{3}$;

freezing temperature: $-18^{\circ} \mathrm{C}$; freezing time: $24 \mathrm{~h}$; thawing temperature: $20^{\circ} \mathrm{C}$; thawing time: $3 \mathrm{~h}$; sample mass: $0.2 \mathrm{~kg}$.

MW power: $800 \mathrm{~W}$; MW power density: $5.33 \mathrm{~W} / \mathrm{g}$; time: $1.50 \mathrm{~min}$; the maximum material temperature: $40^{\circ} \mathrm{C}$; the absolute pressure: $5 \pm 1 \mathrm{kPa}$; the rotational speed of the chamber: $6 \mathrm{rpm}$; sample mass: $0.2 \mathrm{~kg}$.

MW power: $800 \mathrm{~W}$; MW power density: $5.33 \mathrm{~W} / \mathrm{g}$; time: $1.50 \mathrm{~min}$; the maximum material temperature: $40^{\circ} \mathrm{C}$; the absolute pressure in the chamber: $5 \pm 1 \mathrm{kPa}$; the rotational speed of the chamber: 6 rpm; freezing temperature: $-18^{\circ} \mathrm{C}$; freezing time: $24 \mathrm{~h}$; thawing temperature: $20^{\circ} \mathrm{C}$; thawing time: $3 \mathrm{~h}$; sample mass: $0.2 \mathrm{~kg}$.

Freezing temperature: $-18^{\circ} \mathrm{C}$; freezing time: $24 \mathrm{~h}$; thawing temperature: $20^{\circ} \mathrm{C}$; thawing time: $3 \mathrm{~h}$; sample mass: $0.2 \mathrm{~kg}$.

Refrigerant: liquid nitrogen; boiling point of refrigerant: $-196{ }^{\circ} \mathrm{C}$; freezing time: $1 \mathrm{~min}$ (the freezing process was considered completed when the evaporation of liquid nitrogen was no longer observed); thawing temperature: $20^{\circ} \mathrm{C}$; thawing time: $3 \mathrm{~h}$; sample mass: $0.2 \mathrm{~kg}$.

Pulsed vacuum osmotic dehydration (PVOD) time: $2 \mathrm{~h}$ (vacuum: $0.5 \mathrm{~h}$, atmospheric pressure; $1.5 \mathrm{~h}$ ); parameters of PVOD (osmotic solution: sucrose solution; concentration of the osmotic solution: $65^{\circ} \mathrm{Brx}$; the sample to solution ratio: $1: 4$, temperature: $40 \pm 1^{\circ} \mathrm{C}$ ).
Devices

Ultrasonic disruptor Scientz-650E (Ningbo Scientz Biotechnology Co. Ltd., China)

Microwave-vacuum oven (Promis Tech, Wroclaw, Poland)

Liebherr GR 4932 freezer (Liebherr-Hausgeräte GmbH, Ochsenhausen, Germany)

A styrofoam container

Vacuum drying oven DZ ZBC II (Chemland, Stargard Szczecinski, Poland); A water bath (LWT 6/150, WSL, Poland) filled with sucrose solution.
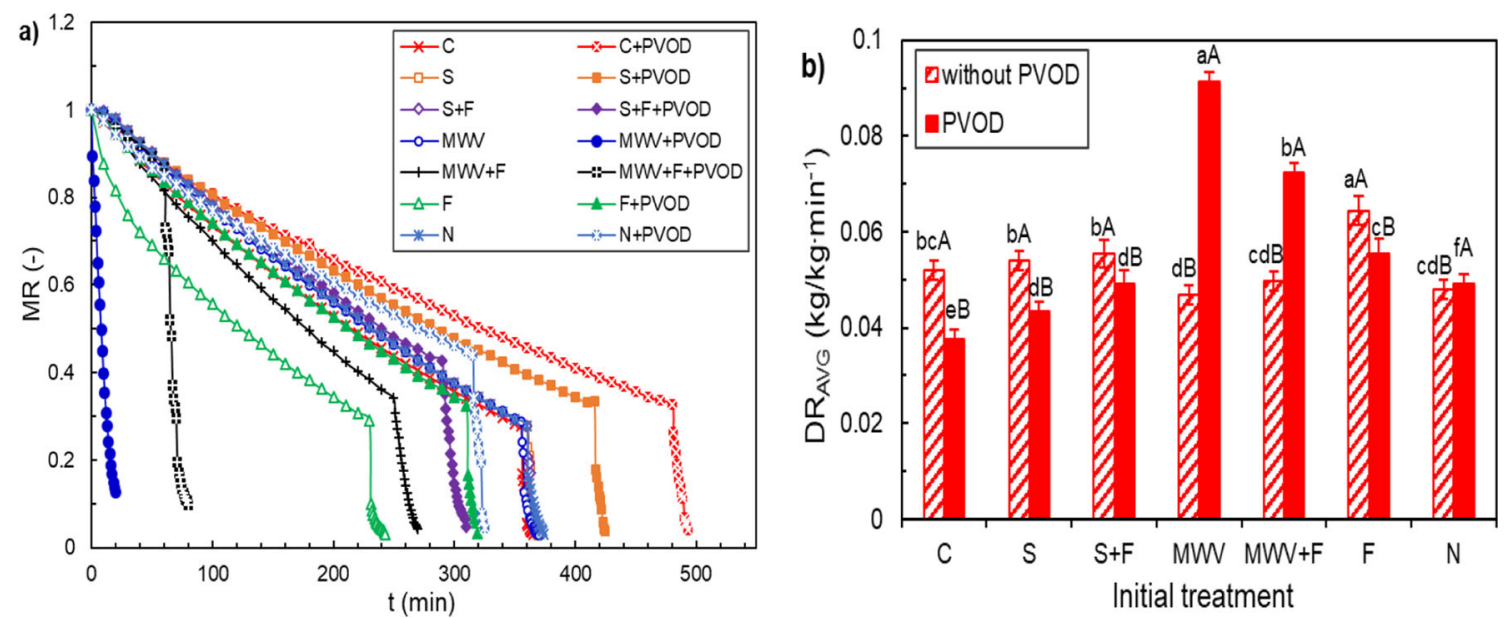

Fig. 1 Moisture ratios of differently pretreated and osmotically dehydrated cranberries vs. HACD+MWVD time (a); average drying rate during HACD+ MWVD of whole cranberries (b) 

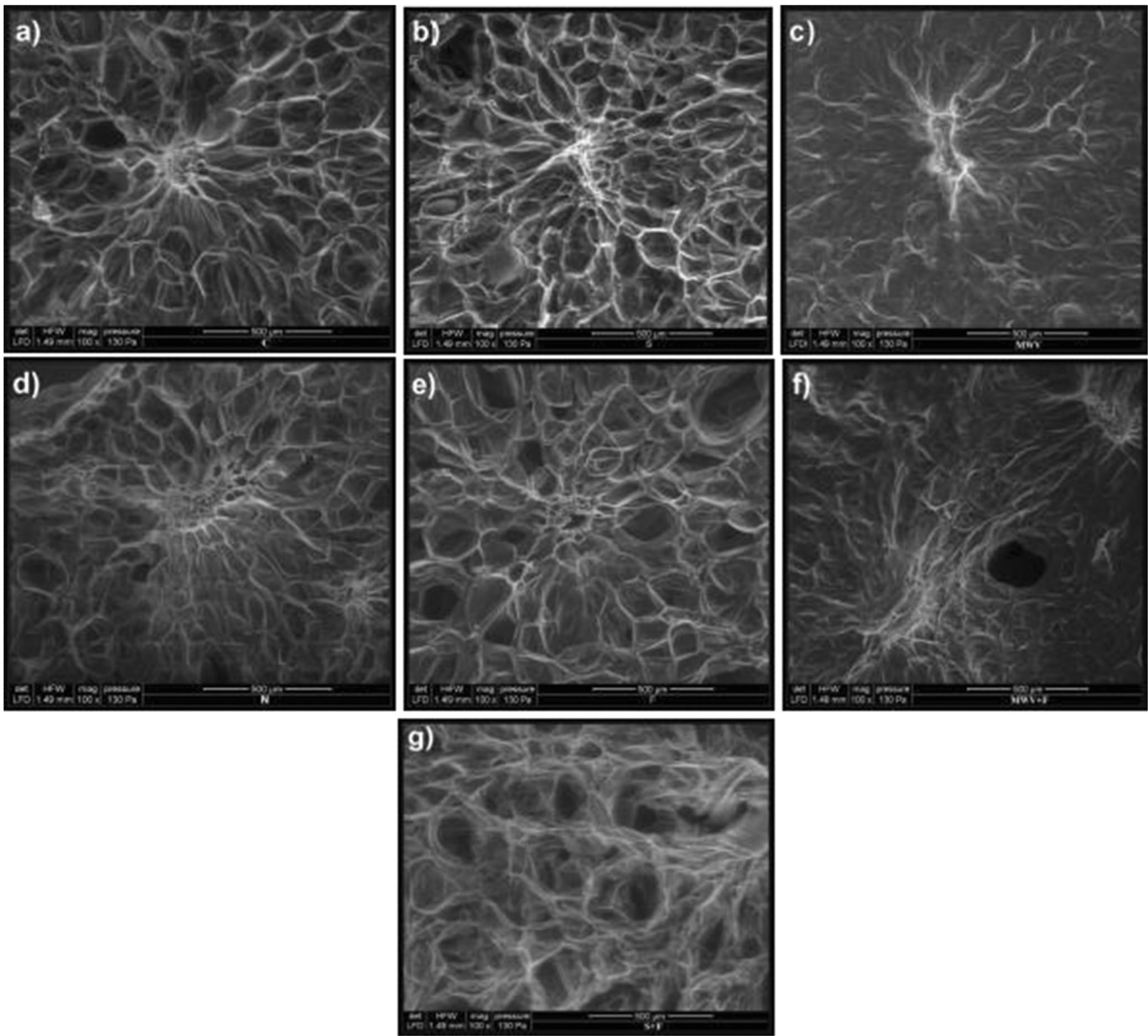

Fig. 2 Micrographs of cross sections (magnification $\times 100$ ) of cranberries subjected to different initial treatments: a C; b S; c MWV; d N; e F; f MWV+F; g S + F

properties (Zielinska and Zielinska 2019; Grace et al. 2012). A seasonal character of production and a high moisture content of fruits make them suitable for processing. Drying can be used to reduce the moisture content, inhibit the growth of microorganisms, and prolong the shelf life of fruits (Liu et al. 2019a). Due to the waxy surface layer which is a barrier to heat and mass transfer processes, hot air drying may take up to 160 hours and negatively affect the physical properties of dried cranberries (Zielinska et al. 2018). Among various drying methods (Liu et al. 2019b; Pereira et al. 2014; Verma et al. 2014), hybrid hot air convective drying and microwavevacuum drying (HACD+MWVD) can be considered an efficient method for drying of berries (Zielinska et al. 2019). It combines the advantages of both single-step HACD and
MWVD. Due to its low cost, HACD is the most frequently used drying method. MWVD is an increasingly popular method that uses microwave radiation to generate heat under reduced pressure. This volumetric heating reduces the drying time and performs a positive impact on the texture and nutritional value of final product (Zhang et al. 2006). Up to date, HACD+MWVD has been successfully applied for drying of e.g., cherries (Nowicka et al. 2015), blueberries (Zielinska et al. 2016), and pomegranate arils (Cano-Lamadrid et al. 2017).

Generally, agricultural materials are subjected to different pretreatments before drying with the aim of quality improvement and drying time reduction (Deng et al. 2019). Among different pretreatments, sonication (S) can be used to increase 

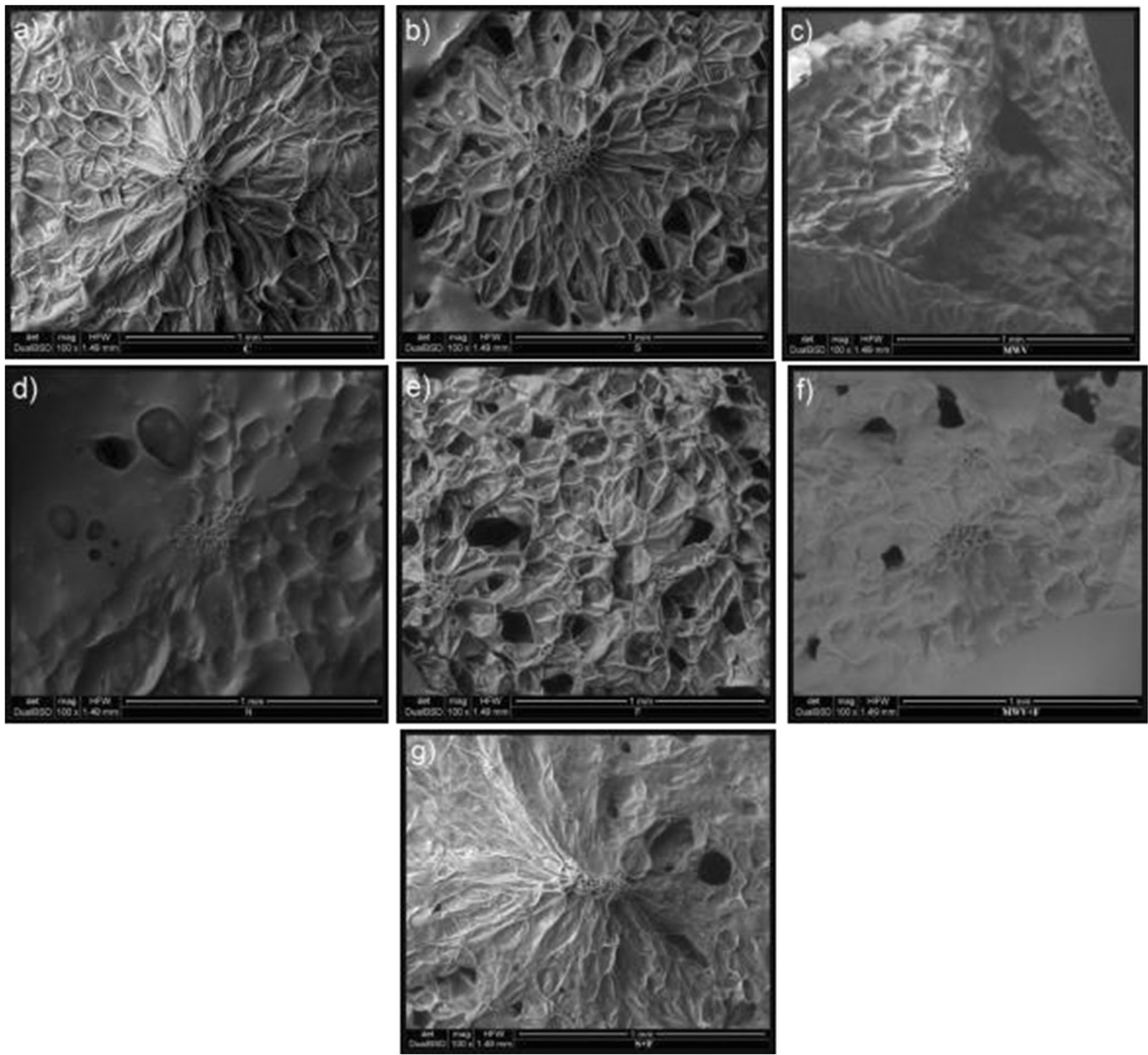

Fig. 3 Micrographs of cross sections (magnification $\times 100$ ) of differently pretreated cranberries subjected to pulsed vacuum osmotic dehydration (PVOD): a C; b S; c MWV; d N; e F; f MWV+F; g S+F

the permeability of skin. The effect of acoustic microstreaming accelerates heat and mass transfer processes (Staniszewska et al. 2019). Microwave-vacuum pretreatment (MWV) may cause volumetric heating, so vapor generated inside the product may develop internal pressure gradients and result in water movement from the interior to the surface of the material (Zhang et al. 2006; Zielinska and Markowski 2018). Convective freezing (F) of fruits before drying may increase the moisture transfer, reduce drying time and energy consumption (Zielinska et al. 2018). Additionally, cryogenic freezing $(\mathrm{N})$ may be used to minimize the formation of large ice crystals and reduce drip losses during freezing thus preserving texture and nutritional value of dehydrated products.
Pulsed vacuum osmotic dehydration (PVOD) in sucrose solution can be used to deliver sweet berries with unique texture, remove some moisture and lower energy consumption during cranberry processing (Ramaswamy and Tola 2014).

There is a general scarcity of research reports on the effect of various pretreatments and PVOD on the HACD+MWVD kinetics and quality of waxy fruits, particularly cranberries. Therefore, the objective of this study was to investigate the effects of sonication (S), microwave-vacuum (MWV), cryogenic freezing $(\mathrm{N})$, convective freezing $(\mathrm{F})$, convective freezing preceded by sonication $(\mathrm{S}+\mathrm{F})$ or convective freezing preceded by microwave-vacuum treatment $(\mathrm{MWV}+\mathrm{F})$ as well as PVOD on the HACD+MWVD drying kinetics, 
Table 2 Effect of initial treatments, PVOD, and HACD+MWVD on the contents of TP, TF, TMA, and FRAP of cranberries

\begin{tabular}{|c|c|c|c|c|c|}
\hline Initial treatment & Dehydration method & TP (mg GAE/g DM) & TF (mg CAE/g DM) & TMA (mg Cy-3G/g DM) & FRAP (mg TE/g DM) \\
\hline \multirow[t]{4}{*}{$\mathrm{C}$} & - & $21.45 \pm 0.17^{\mathrm{aC}}$ & $4.07 \pm 0.03^{\mathrm{aA}}$ & $4.31 \pm 0.02^{\mathrm{bB}}$ & $38.15 \pm 0.25^{\mathrm{aB}}$ \\
\hline & PVOD & $18.41 \pm 0.14^{\mathrm{aD}}$ & $3.78 \pm 0.06^{\mathrm{aB}}$ & $4.62 \pm 0.15^{\mathrm{aA}}$ & $33.58 \pm 0.52^{\mathrm{aC}}$ \\
\hline & HACD+MWVD & $23.90 \pm 0.38^{\mathrm{abB}}$ & $3.79 \pm 0.11^{\mathrm{aB}}$ & $0.75 \pm 0.05^{\mathrm{aD}}$ & $37.56 \pm 0.80^{\mathrm{aB}}$ \\
\hline & PVOD/HACD+MWVD & $25.55 \pm 0.49^{\mathrm{aA}}$ & $2.78 \pm 0.05^{\mathrm{aC}}$ & $1.31 \pm 0.03^{\mathrm{aC}}$ & $45.95 \pm 0.62^{\mathrm{aA}}$ \\
\hline \multirow[t]{4}{*}{ S } & - & $23.30 \pm 0.08^{\mathrm{bA}}$ & $4.56 \pm 0.02^{\mathrm{bA}}$ & $5.12 \pm 0.04^{\mathrm{bA}}$ & $41.99 \pm 0.31^{\mathrm{bA}}$ \\
\hline & PVOD & $20.38 \pm 0.18^{\mathrm{bB}}$ & $3.84 \pm 0.03^{\mathrm{aB}}$ & $3.94 \pm 0.09^{\mathrm{bB}}$ & $37.16 \pm 0.24^{\mathrm{bB}}$ \\
\hline & HACD+MWVD & $27.14 \pm 0.56^{\mathrm{cA}}$ & $3.63 \pm 0.10^{\mathrm{aA}}$ & $2.07 \pm 0.03^{\mathrm{fA}}$ & $47.67 \pm 0.39^{\mathrm{dA}}$ \\
\hline & PVOD/HACD+MWVD & $23.28 \pm 0.44^{\mathrm{bB}}$ & $2.93 \pm 0.1^{\mathrm{aB}}$ & $0.98 \pm 0.04^{\mathrm{cB}}$ & $35.65 \pm 0.64^{\mathrm{cB}}$ \\
\hline \multirow[t]{4}{*}{$S+F$} & - & $22.24 \pm 0.12^{\mathrm{cA}}$ & $3.98 \pm 0.02^{\mathrm{cA}}$ & $4.64 \pm 0.01^{\mathrm{cA}}$ & $39.99 \pm 0.39^{\mathrm{cA}}$ \\
\hline & PVOD & $21.34 \pm 0.17^{\mathrm{cA}}$ & $3.74 \pm 0.03^{\mathrm{aA}}$ & $4.13 \pm 0.04^{\mathrm{abB}}$ & $38.10 \pm 0.48^{\mathrm{bB}}$ \\
\hline & HACD+MWVD & $27.51 \pm 0.56^{\mathrm{cA}}$ & $3.37 \pm 0.08^{\mathrm{bA}}$ & $2.22 \pm 0.06^{\mathrm{gA}}$ & $46.44 \pm 0.62^{\mathrm{cA}}$ \\
\hline & PVOD/HACD+MWVD & $22.72 \pm 0.35^{\mathrm{cB}}$ & $2.87 \pm 0.09^{\mathrm{aB}}$ & $1.32 \pm 0.05^{\mathrm{aB}}$ & $39.47 \pm 0.47^{\mathrm{bB}}$ \\
\hline \multirow[t]{4}{*}{ MWV } & - & $20.94 \pm 0.09^{\mathrm{dA}}$ & $4.00 \pm 0.03^{\mathrm{acA}}$ & $4.16 \pm 0.04^{\mathrm{cA}}$ & $39.37 \pm 0.38^{\mathrm{cA}}$ \\
\hline & PVOD & $10.78 \pm 0.08^{\mathrm{fB}}$ & $2.15 \pm 0.04^{\mathrm{dB}}$ & $2.00 \pm 0.03^{\mathrm{eB}}$ & $21.50 \pm 0.20^{\mathrm{dB}}$ \\
\hline & HACD+MWVD & $23.30 \pm 0.28^{\mathrm{aA}}$ & $2.65 \pm 0.05^{\mathrm{eA}}$ & $1.28 \pm 0.01^{\mathrm{cA}}$ & $38.82 \pm 0.55^{\mathrm{aA}}$ \\
\hline & PVOD/HACD+MWVD & $13.01 \pm 0.44^{\mathrm{fB}}$ & $1.56 \pm 0.06^{\mathrm{cB}}$ & $0.63 \pm 0.03^{\mathrm{eB}}$ & $17.59 \pm 0.36^{\mathrm{fB}}$ \\
\hline \multirow[t]{4}{*}{$\mathrm{MWV}+\mathrm{F}$} & - & $21.42 \pm 0.20^{\mathrm{adA}}$ & $3.91 \pm 0.04^{\mathrm{cA}}$ & $4.32 \pm 0.05^{\mathrm{aA}}$ & $42.23 \pm 0.48^{\mathrm{bA}}$ \\
\hline & PVOD & $10.46 \pm 0.06^{\mathrm{gB}}$ & $2.10 \pm 0.04^{\mathrm{dB}}$ & $1.66 \pm 0.01^{\mathrm{fB}}$ & $20.52 \pm 0.36^{\mathrm{eB}}$ \\
\hline & HACD+MWVD & $25.85 \pm 0.30^{\mathrm{bA}}$ & $3.10 \pm 0.08^{\mathrm{cA}}$ & $1.93 \pm 0.02^{\mathrm{eA}}$ & $46.40 \pm 0.81^{\mathrm{cA}}$ \\
\hline & PVOD/HACD+MWVD & $12.05 \pm 0.32^{\mathrm{gB}}$ & $1.74 \pm 0.07^{\mathrm{bB}}$ & $0.86 \pm 0.03^{\mathrm{dB}}$ & $20.34 \pm 0.55^{\mathrm{eB}}$ \\
\hline \multirow[t]{4}{*}{$\mathrm{F}$} & - & $22.14 \pm 0.26^{\mathrm{acA}}$ & $3.53 \pm 0.05^{\mathrm{dA}}$ & $3.30 \pm 0.02^{\mathrm{dA}}$ & $38.67 \pm 0.42^{\mathrm{acA}}$ \\
\hline & PVOD & $16.12 \pm 0.11^{\mathrm{dB}}$ & $2.91 \pm 0.04^{\mathrm{bB}}$ & $2.69 \pm 0.02^{\mathrm{cB}}$ & $29.25 \pm 0.31^{\mathrm{cB}}$ \\
\hline & HACD+MWVD & $22.14 \pm 0.49^{\mathrm{dA}}$ & $2.91 \pm 0.07^{\mathrm{dA}}$ & $0.88 \pm 0.01^{\mathrm{bB}}$ & $33.03 \pm 0.72^{\mathrm{eB}}$ \\
\hline & PVOD/HACD+MWVD & $22.30 \pm 0.34^{\mathrm{dA}}$ & $2.79 \pm 0.15^{\mathrm{aA}}$ & $1.19 \pm 0.02^{\mathrm{bA}}$ & $36.75 \pm 0.36^{\mathrm{cA}}$ \\
\hline \multirow[t]{4}{*}{$\mathrm{N}$} & - & $21.32 \pm 0.19^{\mathrm{adA}}$ & $4.08 \pm 0.04^{\mathrm{aA}}$ & $4.30 \pm 0.02^{\mathrm{aA}}$ & $38.02 \pm 0.23^{\mathrm{aA}}$ \\
\hline & PVOD & $15.21 \pm 0.16^{\mathrm{eB}}$ & $2.75 \pm 0.02^{\mathrm{cB}}$ & $2.90 \pm 0.02^{\mathrm{dB}}$ & $30.23 \pm 0.32^{\mathrm{cB}}$ \\
\hline & HACD+MWVD & $24.14 \pm 0.44^{\mathrm{aA}}$ & $2.93 \pm 0.06^{\mathrm{dA}}$ & $1.48 \pm 0.08^{\mathrm{dA}}$ & $42.41 \pm 0.68^{\mathrm{bA}}$ \\
\hline & PVOD/HACD+MWVD & $17.20 \pm 0.38^{\mathrm{eB}}$ & $1.88 \pm 0.09^{\mathrm{bB}}$ & $0.68 \pm 0.03^{\mathrm{eB}}$ & $25.44 \pm 0.59^{\mathrm{dB}}$ \\
\hline
\end{tabular}

Same letters in the same column indicate that the mean values are not significantly different at a confidence level of $95 \%(p<0.05)$. ${ }^{\text {ab }}$ Significant differences between samples subjected to the same dehydration method but different initial treatments. ${ }^{\mathrm{AB}}$ Significant differences between samples subjected to the same initial treatment but different dehydration method

texture, color, and the content of bioactive compounds of cranberries.

\section{Materials and Methods}

\section{Materials}

Cranberries (V. macrocarpon L.) were purchased from a farm in Lublin region, Poland. To ensure the uniformity of physical characteristics, cranberries with the same size, firmness, and color were selected. The initial moisture content of raw cranberries was $7.49 \pm 0.02 \mathrm{~kg} \mathrm{H}_{2} \mathrm{O} / \mathrm{kg} \mathrm{DM}$ (dry matter) determined using vacuum drying oven at the temperature of $70{ }^{\circ} \mathrm{C}$ for $24 \mathrm{~h}$ (AOAC 2002).

\section{Pretreatments, Pulsed Vacuum Osmotic Dehydration, and Drying Procedures}

A detailed description of pretreatments and devices used for initial pretreatments and pulsed vacuum osmotic dehydration (PVOD) is shown in Table 1. All of the pretreatments were carried out in triplicate. After pretreatments and PVOD, the whole cranberries were subjected to combined hot air convective drying and microwavevacuum drying (HACD+MWVD). The mass of cranberries used in each drying experiment was $0.150 \pm$ $0.001 \mathrm{~kg}$. Initially, cranberries were subjected to HACD at the temperature of $80{ }^{\circ} \mathrm{C}$. HACD was conducted in a drying oven (FED53 127 Binder, USA). The mass of samples was monitored and recorded every $10 \mathrm{~min}$ by a digital balance with accuracy of $0.001 \mathrm{~g}$ during drying. 
Table 3 Effect of initial treatments and PVOD on the textural properties of raw and pretreated cranberries

\begin{tabular}{llll}
\hline Initial treatment & Dehydration method & $\begin{array}{l}\text { Cutting test } \\
\text { F }(N)\end{array}$ & $\begin{array}{l}\text { Puncture test } \\
F(N)\end{array}$ \\
\hline $\mathrm{C}$ & - & $33.06 \pm 1.65^{\mathrm{aA}}$ & $6.86 \pm 0.12^{\mathrm{aA}}$ \\
& PVOD & $25.12 \pm 0.92^{\mathrm{aB}}$ & $5.47 \pm 0.16^{\mathrm{aB}}$ \\
$\mathrm{S}$ & - & $30.74 \pm 0.98^{\mathrm{aA}}$ & $6.86 \pm 0.19^{\mathrm{aA}}$ \\
& PVOD & $25.92 \pm 0.95^{\mathrm{aB}}$ & $5.85 \pm 0.17^{\mathrm{bB}}$ \\
$\mathrm{S}+\mathrm{F}$ & - & $27.83 \pm 0.68^{\mathrm{bA}}$ & $4.90 \pm 0.12^{\mathrm{bA}}$ \\
& PVOD & $20.73 \pm 0.99^{\mathrm{bB}}$ & $4.69 \pm 0.14^{\mathrm{cdA}}$ \\
$\mathrm{MWV}$ & - & $11.85 \pm 0.52^{\mathrm{eA}}$ & $4.86 \pm 0.24^{\mathrm{bA}}$ \\
& PVOD & $11.74 \pm 0.74^{\mathrm{dA}}$ & $4.41 \pm 0.17^{\mathrm{dB}}$ \\
$\mathrm{MWV}+\mathrm{F}$ & - & $13.52 \pm 0.85^{\mathrm{dA}}$ & $4.91 \pm 0.20^{\mathrm{bA}}$ \\
& PVOD & $13.52 \pm 0.85^{\mathrm{cA}}$ & $4.50 \pm 0.17^{\mathrm{dB}}$ \\
$\mathrm{F}$ & - & $26.50 \pm 1.02^{\mathrm{bA}}$ & $4.84 \pm 0.11^{\mathrm{bA}}$ \\
& PVOD & $19.50 \pm 0.70^{\mathrm{bB}}$ & $5.01 \pm 0.18^{\mathrm{cA}}$ \\
$\mathrm{N}$ & - & $22.86 \pm 0.76^{\mathrm{cA}}$ & $4.72 \pm 0.18^{\mathrm{bA}}$ \\
& PVOD & $19.93 \pm 0.69^{\mathrm{bB}}$ & $4.47 \pm 0.14^{\mathrm{dA}}$ \\
\hline
\end{tabular}

Table shows mean values with standard deviations of the mean (the results were averaged over nine measurements). F, force; N. Same letters in the same column indicate that the mean values are not significantly different at a confidence level of $95 \%(p<0.05)$. ${ }^{\text {ab }}$ Significant differences between samples subjected to the same dehydration method but different initial treatments. ${ }^{\mathrm{AB}}$ Significant differences between samples subjected to the same initial treatment but different dehydration Method

When the moisture content of cranberries was reduced to about $2.00 \mathrm{~kg} \mathrm{H}_{2} \mathrm{O} / \mathrm{kg} \mathrm{DM}$, the samples were transferred to MWVD. MWVD was conducted at microwave power of $150 \mathrm{~W}$ and absolute pressure of $5 \pm 1 \mathrm{kPa}$. MWVD was continued until the temperature of material increased suddenly up to $80^{\circ} \mathrm{C}$. All of the drying experiments were done in triplicate.

\section{Drying Curves}

Moisture ratios (MR) were computed based on the initial $\left(\mathrm{MC}_{0}\right)$, actual $\left(\mathrm{MC}_{(\mathrm{t})}\right)$, and equilibrium $\left(\mathrm{MC}_{\mathrm{e}}\right)$ moisture content. MR represents the amount of moisture remaining in the samples reported to the initial moisture content. The MR of the samples during the drying process was calculated from the formula (Zielinska et al. 2016):

$M R=\frac{M C_{(t)}-M C_{e}}{M C_{0}-M C_{e}}$

Mathematical differentiation of the drying curves allowed calculating the drying rates (DR) (Zielinska and Markowski 2010). DR was not constant during drying of cranberries and the average drying rate $\left(\mathrm{DR}_{\mathrm{AVG}}\right)$ was calculated and presented as the mean value.

\section{Determination of Textural Properties}

Texture Analyzer TA.HD Plus (Stable Micro Systems, Godalming, UK) was used to determine the texture of cranberries. Cutting and puncture tests were applied to test every single raw and pretreated fruit. The test speed was set at $2 \mathrm{~mm} /$ $\mathrm{s}$. Both tests were performed perpendicularly to the petiole axis. Texture of dried fruits was evaluated by texture profile analysis (TPA) using a $50 \mathrm{~mm}$-diameter flat piston at $50 \%$ strain. The test speed was set at $2 \mathrm{~mm} / \mathrm{s}$. The hardness, springiness, cohesiveness, gumminess, and chewiness of dried products were obtained from the force-deformation curve (Zielinska et al. 2015). The results were averaged over 15 measurements.

\section{Microscopic Observations}

The cross-sections of raw (non-treated) and pretreated cranberries were observed using an environment scanning electron ESEM (ESEM, Quanta 200, FEI Company, Netherlands). Fruits were cut along the perpendicular axis with a scalpel and observed under ESEM without any prior preparation. The microscopic magnification was $\times 100$, while pressure was $130 \mathrm{~Pa}$.

\section{Determination of Total Phenolics, Total Flavonoids, Total Monomeric Anthocyanin Contents, and Ferric Reducing Antioxidant Power}

The mass of $0.05 \mathrm{~g}$ of cranberries was extracted with solvent ( $80 \%$ aqueous methanol solution containing $0.1 \% \mathrm{HCl}(\mathrm{v} / \mathrm{v})$ ) by triple sonication ( $30 \mathrm{~s})$ and vortexing ( $30 \mathrm{~s})$, and then the mixture centrifugation (13200 g) for $10 \mathrm{~min}$. This procedure was conducted five times on the residue with the volume of 1 $\mathrm{mL}$ of the solvent. Extraction procedure was carried out in triplicate. The total phenolics (TP), total flavonoids (TF), total monomeric anthocyanins (TMA), and ferric reducing antioxidant power (FRAP) assay were determined according to the method of Zielinska and Zielinska (2019) with some modifications. All measurements were performed in triplicate using UV-1800 spectrophotometer (Shimadzu, Kyoto, Japan).

\section{Color Measurement}

Color of cranberries was determined by the Miniscan XE Plus spectrophotometer. A container filled with $50 \mathrm{~g}$ of fruits was positioned over the sample port and the color of sample surface was measured vertically through the glass bottom. A CIE standard illuminant $\mathrm{D} 65,10^{\circ}$ observer, and $8^{\circ}$ diaphragm were applied to measure color parameters of cranberries in CIE $L^{*} a^{*} b^{*}$ space. All of the measurements were averaged over 35 measurements. 
Table 4 Effect of initial treatments, PVOD, and HACD+MWVD on the textural properties of dried cranberries

\begin{tabular}{|c|c|c|c|c|c|c|c|c|}
\hline $\begin{array}{l}\text { Initial } \\
\text { treatment }\end{array}$ & Dehydration method & $\mathrm{H}(\mathrm{N})$ & $\mathrm{Co}(-)$ & $\mathrm{S}(-)$ & $\mathrm{G}(-)$ & $\mathrm{Ch}(\mathrm{N})$ & $\rho_{\mathrm{p}}\left(\mathrm{kg} / \mathrm{m}^{3}\right)$ & $\varepsilon_{\mathrm{p}}(-)$ \\
\hline \multirow[t]{2}{*}{$\mathrm{C}$} & HACD+MWVD & $19 \pm 2^{\mathrm{efA}}$ & $0.33 \pm 0.09^{\mathrm{eA}}$ & $0.62 \pm 0.09^{\mathrm{fgA}}$ & $5.8 \pm 2.9^{\operatorname{defg} \mathrm{A}}$ & $3.5 \pm 1.5^{\operatorname{defA}}$ & $196 \pm 14^{\mathrm{fA}}$ & $86.1 \pm 1.0^{\mathrm{dB}}$ \\
\hline & $\begin{array}{l}\text { PVOD/HACD+ } \\
\text { MWVD }\end{array}$ & $18 \pm 1^{\mathrm{fA}}$ & $0.37 \pm 0.01^{\mathrm{deA}}$ & $0.66 \pm 0.02^{\text {cdefA }}$ & $6.9 \pm 0.4^{\mathrm{dA}}$ & $4.6 \pm 0.3^{\mathrm{deA}}$ & $167 \pm 5^{\mathrm{gB}}$ & $88.0 \pm 0.3^{\mathrm{bcA}}$ \\
\hline \multirow[t]{2}{*}{ S } & HACD+MWVD & $7 \pm 4^{\mathrm{gA}}$ & $0.44 \pm 0.05^{\text {abceA }}$ & $0.63 \pm 0.12^{\mathrm{efgA}}$ & $2.9 \pm 1.6^{\mathrm{fB}}$ & $1.8 \pm 1.0^{\mathrm{gfB}}$ & $158 \pm 10^{\mathrm{gB}}$ & $88.8 \pm 0.7^{\mathrm{bA}}$ \\
\hline & $\begin{array}{l}\text { PVOD/HACD+ } \\
\text { MWVD }\end{array}$ & $22 \pm 1^{\mathrm{deA}}$ & $0.35 \pm 0.01^{\mathrm{deB}}$ & $0.64 \pm 0.01^{\operatorname{defg} A}$ & $7.6 \pm 0.4^{\mathrm{dA}}$ & $4.9 \pm 0.3^{\mathrm{dA}}$ & $194 \pm 11^{\mathrm{fA}}$ & $86.2 \pm 0.8^{\mathrm{dB}}$ \\
\hline \multirow[t]{2}{*}{$S+F$} & HACD+MWVD & $21 \pm 8^{\text {cdfA }}$ & $0.03 \pm 0.01^{\mathrm{gB}}$ & $0.21 \pm 0.21^{\mathrm{iB}}$ & $0.7 \pm 0.9^{\mathrm{hB}}$ & $0.3 \pm 0.5^{\mathrm{gB}}$ & $158 \pm 7^{\mathrm{gB}}$ & $88.8 \pm 0.5^{\mathrm{bA}}$ \\
\hline & $\begin{array}{l}\text { PVOD/HACD+ } \\
\text { MWVD }\end{array}$ & $29 \pm 2^{\mathrm{cA}}$ & $0.22 \pm 0.02^{\mathrm{fA}}$ & $0.55 \pm 0.04^{\mathrm{hA}}$ & $6.5 \pm 0.8^{\mathrm{deA}}$ & $3.9 \pm 0.5^{\mathrm{eA}}$ & $293 \pm 21^{\mathrm{dA}}$ & $79.2 \pm 1.5^{\mathrm{fB}}$ \\
\hline \multirow[t]{2}{*}{ MWV } & HACD+MWVD & $5 \pm 2^{\mathrm{gB}}$ & $0.49 \pm 0.08^{\text {abceA }}$ & $0.79 \pm 0.09^{\text {abefA }}$ & $2.1 \pm 0.8^{\mathrm{gB}}$ & $1.7 \pm 0.7^{\mathrm{fB}}$ & $248 \pm 12^{\mathrm{eB}}$ & $82.4 \pm 0.9^{\mathrm{eA}}$ \\
\hline & $\begin{array}{l}\text { PVOD/HACD+ } \\
\text { MWVD }\end{array}$ & $44 \pm 5^{\mathrm{bA}}$ & $0.46 \pm 0.01^{\mathrm{bA}}$ & $0.68 \pm 0.02^{\text {bcefA }}$ & $19.1 \pm 1.8^{\mathrm{bA}}$ & $12.3 \pm 1.0^{\mathrm{bA}}$ & $639 \pm 10^{\mathrm{bA}}$ & $54.7 \pm 0.7^{\mathrm{hB}}$ \\
\hline \multirow[t]{2}{*}{$M W V+F$} & HACD+MWVD & $46 \pm 18^{\mathrm{bcB}}$ & $0.44 \pm 0.03^{\mathrm{bceA}}$ & $0.74 \pm 0.05^{\text {abefA }}$ & $20.2 \pm 7.6^{\mathrm{bB}}$ & $14.8 \pm 5.4^{\mathrm{abA}}$ & $299 \pm 13^{\mathrm{dB}}$ & $78.7 \pm 0.9^{\mathrm{fA}}$ \\
\hline & $\begin{array}{l}\text { PVOD/HACD+ } \\
\text { MWVD }\end{array}$ & $101 \pm 8^{\mathrm{aA}}$ & $0.41 \pm 0.01^{\mathrm{ceA}}$ & $0.51 \pm 0.02^{\mathrm{hB}}$ & $41.4 \pm 3.5^{\mathrm{aA}}$ & $20.3 \pm 1.4^{\mathrm{aA}}$ & $689 \pm 15^{\mathrm{aA}}$ & $51.1 \pm 1.1^{\mathrm{iB}}$ \\
\hline \multirow[t]{2}{*}{$\mathrm{F}$} & HACD+MWVD & $26 \pm 3^{\mathrm{cB}}$ & $0.20 \pm 0.04^{\mathrm{fA}}$ & $0.66 \pm 0.04^{\text {bcefA }}$ & $5.0 \pm 1.1^{\mathrm{efB}}$ & $3.3 \pm 0.9^{\mathrm{efB}}$ & $119 \pm 9^{\mathrm{hB}}$ & $91.5 \pm 0.6^{\mathrm{aA}}$ \\
\hline & $\begin{array}{l}\text { PVOD/HACD+ } \\
\text { MWVD }\end{array}$ & $38 \pm 3^{\mathrm{bA}}$ & $0.27 \pm 0.03^{\mathrm{fA}}$ & $0.60 \pm 0.03^{\mathrm{gB}}$ & $10.8 \pm 1.4^{\mathrm{cA}}$ & $7.0 \pm 1.0^{\mathrm{cA}}$ & $170 \pm 9^{\mathrm{gA}}$ & $87.9 \pm 0.6^{\mathrm{bcB}}$ \\
\hline \multirow[t]{2}{*}{$\mathrm{N}$} & HACD+MWVD & $9 \pm 3^{\mathrm{gA}}$ & $0.50 \pm 0.04^{\mathrm{abA}}$ & $0.72 \pm 0.11^{\text {abcdefgA }}$ & $4.7 \pm 1.8^{\mathrm{efg} A}$ & $3.4 \pm 1.6^{\mathrm{defA}}$ & $175 \pm 8^{\mathrm{gB}}$ & $87.6 \pm 0.6^{\mathrm{cdA}}$ \\
\hline & $\begin{array}{l}\text { PVOD/HACD+ } \\
\text { MWVD }\end{array}$ & $11 \pm 1^{\mathrm{gA}}$ & $0.50 \pm 0.01^{\mathrm{aA}}$ & $0.77 \pm 0.02^{\mathrm{aeA}}$ & $5.8 \pm 0.5^{\mathrm{eA}}$ & $4.5 \pm 0.4^{\mathrm{deA}}$ & $580 \pm 19^{\mathrm{cA}}$ & $58.9 \pm 1.4^{\mathrm{gB}}$ \\
\hline
\end{tabular}

Table shows mean values with standard deviations of the mean (the results were averaged over twenty five measurements). Mechanical and physical properties of raw sample (before drying): H: $63.7 \pm 2.5 \mathrm{~N}$; Co: $0.23 \pm 0.01,-; \mathrm{S}: 0.71 \pm 0.01,-; \mathrm{G}: 14.4 \pm 0.9,-; \mathrm{Ch}: 10.2 \pm 0.8, \mathrm{~N} ; \rho_{\mathrm{p}}: 683 \pm 6, \mathrm{~kg} / \mathrm{m}^{3}$; $\varepsilon_{\mathrm{p}}: 51.2 \pm 0.4,-$. Same letters in the same column indicate that the mean values are not significantly different at a confidence level of $95 \%(p<0.05)$. ${ }^{\mathbf{a b}}$ Significant differences between samples subjected to the same dehydration method but different initial treatments. ${ }^{\mathbf{A B}}$ Significant differences between samples subjected to the same initial treatment but different dehydration method. Symbols: H: hardness, N; Co: cohesiveness, -; S: springiness, -; G: gumminess, -; Ch: chewiness, $\mathrm{N} ; \rho_{\mathrm{p}}$ : particle density, $\mathrm{kg} / \mathrm{m}^{3} ; \varepsilon_{\mathrm{p}}$ : particle porosity, ${ }^{-}$

\section{Statistical Analysis}

Statistical analyses were done using the STATISTICA 12.0 software (StatSoft Inc., Tulsa, OK, USA). One-way analysis of variance was used for testing the differences between samples. Significant differences were determined using Mann Whitney $U$ test $(p<0.05)$.

\section{Results and Discussion}

\section{Effect of Pretreatments and PVOD on HACD+MWVD Drying Kinetics of Whole Cranberries}

Drying of non-osmotically dehydrated fruits took from 243 to $374 \mathrm{~min}$, while $\mathrm{DR}_{\mathrm{AVG}}$ was from $0.047 \pm 0.002$ to $0.064 \pm$ $0.003 \mathrm{~kg} \mathrm{H}_{2} \mathrm{O} / \mathrm{kg} \mathrm{DM} / \mathrm{min}$ (Figs. 1a and 1b). Figure 1a presents two stages of drying process. The first stage is hot air convective drying process. HACD curves decreased gently due to the relatively low drying rate. When the moisture content of HACD materials reached around $2.00 \mathrm{~kg} \mathrm{H}_{2} \mathrm{O} / \mathrm{kg} \mathrm{DM}$, partially dried fruit was transferred to the second MWVD stage. Thus, the drying rate increased rapidly and steeply decreased in the final stage of drying. The fruits subjected to MWV and PVOD did not require HACD stage, and MWVD took in this case only $20 \mathrm{~min}$. The changes in drying kinetics are related to the changes in the microstructure of processed fruits (Figs. 2 and 3).

\section{Effect of Pretreatments, PVOD, and HACD+MWVD on the Content of Bioactive Compounds and Antioxidant Activity of Cranberries}

The TP content of dried fruits without any pretreatment was $23.90 \pm 0.38 \mathrm{mg} \mathrm{GAE} / \mathrm{g}$ DM, while non-treated fruits subjected to combined PVOD and HACD+MWVD were characterized by higher TP content, i.e., $25.55 \pm 0.49 \mathrm{mg} \mathrm{GAE} / \mathrm{g} \mathrm{DM}$ (Table 2). In terms of TF content, no treatment or sonication ( $\mathrm{S}$ or $\mathrm{S}+\mathrm{F}$ ) can be applied to produce high value-added dried sour snacks or sweet cranberries. TMA content of fruits decreased dramatically during HACD+MWVD or combined PVOD and HACD+MWVD. Anthocyanins were particularly sensitive to thermal degradation and losses during osmotic dehydration due to leaching into osmotic solution (Mundada et al. 2010). 


\section{Effect of Pretreatments and PVOD on the Texture of Cranberries}

Various pretreatments except sonication (S) significantly decreased, i.e., from 16 to $64 \%$, the resistance of cranberry skin in cutting test, while decrease in puncture force was from 28 to $31 \%$ (Table 3). Compared with non-treated cranberries, MWV resulted in a number of microfissures and cracks on the fruit surface layer and thus less springy and resistant fruit's skin in cutting test (Fig. 2). Cryogenic freezing (N) significantly reduced hardness of fruits, while convective freezing (F) or other techniques combined with F ( S + F or MWV + F) significantly increased hardness of dried fruits (Table 4). Low hardness of cryogenically frozen fruits could result from freeze-cracking that appeared under high freezing rate of whole cranberries (Zielinska et al. 2019).

\section{Effect of Pretreatments, PVOD, and HACD+MWVD on Color Parameters and Overall Appearance of Cranberries}

No treatment or sonication (S) resulted in quite high $L^{*}$ values of HACD+MWVD fruits (Table 5). The $L^{*}$ values of HACD+ MWVD samples pretreated other way were lower than that of

Table 5 Effect of initial treatments, PVOD, and HACD+MWVD on the color parameters and overall appearance of whole cranberries

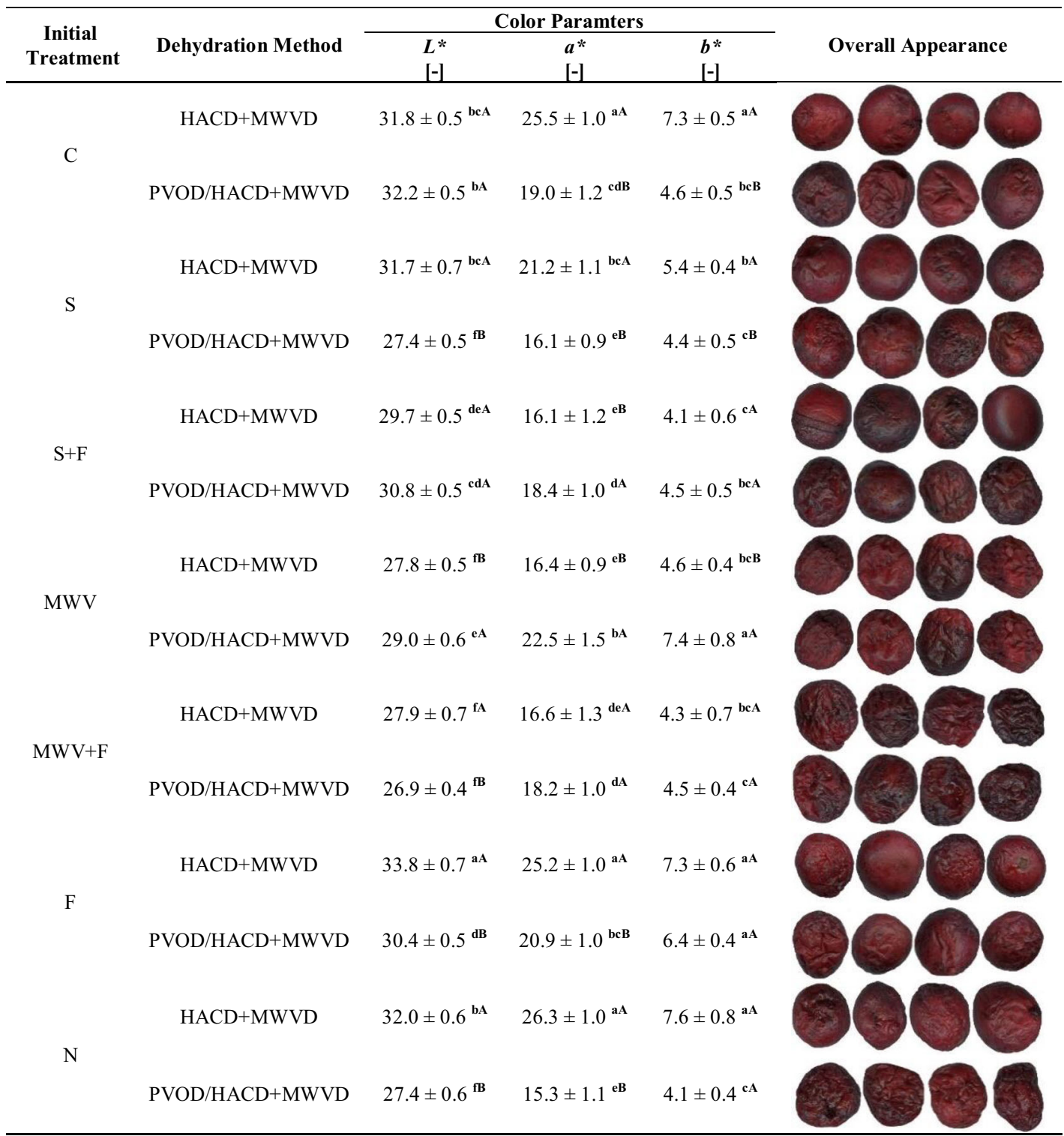

Table shows mean values with standard deviations of the mean (the results were averaged over thirty five measurements). Same letters in the same column indicate that the mean values are not significantly different at a confidence level of $95 \%(p<0.05) .{ }^{\mathbf{a b}}$ - Significant differences between samples subjected to different initial treatments. ${ }^{\mathbf{A B}}$ - significant differences between osmotically dehydrated and non-dehydrated samples. Color parameters of raw sample: $L^{*}: 31.1 \pm 0.2,-; a^{*}: 22.5 \pm 0.6,-; b^{*}: 8.4 \pm 0.4,-. L^{*}$ :lightness, $-; a^{*}$ : redness, $-; b^{*}$ : yellowness 
raw fruits. Dried fruits pretreated by MWV were characterized by the lowest $L^{*}$ values. Initial treatment decreased lightness of osmotically dehydrated and HACD+MWVD fruits. Pretreatments and PVOD influenced the drying time and the surface structure of HACD+MWVD of cranberries. In the case of PVOD and dried fruits, MWV pretreatment produced berries of the most intensive red and yellow color, but the overall appearance was less attractive and fruits appeared to be flattened and wrinkled (Table 5).

\section{Conclusions}

Results showed that drying time of cranberries varied from 20 to $493 \mathrm{~min}$. HACD+MWVD produced high value added products, i.e., crispy sour berries of attractive color and high TP content and FRAP values. MWV, S, and $\mathrm{N}$ resulted in low hardness of HACD+MWVD fruits. PVOD and HACD+MWVD yielded sweet fruits of flat and wrinkled appearance and much lower nutritional value. It increased hardness of dried berries, while MWV caused significant hardening of their surface. PVOD resulted in high losses of bioactive compounds. HACD+MWVD seems to be good alternative for single-step HACD and singlestep MWVD as well as PVOD and HACD+MWVD of cranberries. The results of this study provide useful data for manufacturers, suppliers, and consumers of waxy fruits and vegetables.

Funding Information This study was supported by research grant no. 2015/17/B/NZ9/03601 from the National Science Center in Poland and partially supported by the University of Warmia and Mazury in Olsztyn (grant no. 16.610.001-110).

Open Access This article is licensed under a Creative Commons Attribution 4.0 International License, which permits use, sharing, adaptation, distribution and reproduction in any medium or format, as long as you give appropriate credit to the original author(s) and the source, provide a link to the Creative Commons licence, and indicate if changes were made. The images or other third party material in this article are included in the article's Creative Commons licence, unless indicated otherwise in a credit line to the material. If material is not included in the article's Creative Commons licence and your intended use is not permitted by statutory regulation or exceeds the permitted use, you will need to obtain permission directly from the copyright holder. To view a copy of this licence, visit http://creativecommons.org/licenses/by/4.0/.

\section{References}

AOAC. (2002). Official methods of analysis, Method number 934.06. USA: Association of Official Analytical Chemists Arlington.

Cano-Lamadrid, M., Lech, K., Michalska, A., Wasilewska, M., Figiel, A., Wojdylo, A., \& Carbonell-Barrachina, A. A. (2017). Influence of osmotic dehydration pre-treatment and combined drying method on physicochemical and sensory properties of pomegranate arils, cultivar Mollar de Elche. Food Chemistry, 232, 306-315.

Deng, L. Z., Mujumdar, A. S., Zhang, Q., Yang, X. H., Wang, J., Zheng, Z. A., \& Xiao, H. W. (2019). Chemical and physical pretreatments of fruits and vegetables: effects on drying characteristics and quality attributes -a comprehensive review. Critical Reviews in Food Science and Nutrition, 59(9), 1408-1432.
Grace, M. H., Massey, A., Mbeunkui, F., Yousef, G. G., \& Lila, M. A. (2012). Comparison of health-relevant flavonoids in commonly consumed cranberry products. Journal of Food Science, 77(8), H176-H183.

Liu, Z. L., Bai, J. W., Wang, S. X., Meng, J. S., Wang, H., Yu, X. L., Gao, Z. J., \& Xiao, H. W. (2019a). Prediction of energy and exergy of mushroom slices drying in hot air impingement dryer by artificial neuron network. Drying Technology, 1-12. https://doi.org/10.1080/ 07373937.2019.1607873.

Liu, Z. L., Bai, J. W., Yang, W. X., Wang, J., Deng, L. Z., Yu, X. L., Zheng, Z. A., Gao, Z. J., \& Xiao, H. W. (2019b). Effect of highhumidity hot air impingement blanching (HHAIB) and drying parameters on drying characteristics and quality of broccoli florets. Drying Technology, 37(10), 1251-1264.

Mundada, M., Singh, B., \& Maske, S. (2010). Optimisation of processing variables affecting the osmotic dehydration of pomegranate arils. International Journal of Food Science \& Technology, 45(8), 1732-1738.

Nowicka, P., Wojdylo, A., Lech, K., \& Figiel, A. (2015). Influence of osmodehydration pretreatment and combined drying method on the bioactive potential of sour cherry fruits. Food and Bioprocess Technology, 8(4), 824-836.

Pereira, A. L. F., Almeida, F. D. L., Lima, M. A., da Costa, C. J. M., \& Rodrigues, S. (2014). Spray-drying of probiotic cashew apple juice. Food and Bioprocess Technology, 7(9), 2492-2499.

Ramaswamy, H. S., \& Tola, Y. (2014). Energy considerations in osmotic dehydration. In Modern drying technology. Eds.: Tsotsas E., Mujumbar, A.S. Weinheim, Germany: WileyVCH Verlag GmbH \& Co. KGaA.

Staniszewska, I., Staszynski, S., \& Zielinska, M. (2019). Application of sonication and freezing as initial treatments before microwavevacuum drying of cranberries. Technical Sciences, 22(2), 151-167.

Verma, D., Kaushik, N., \& Rao, P. S. (2014). Application of high hydrostatic pressure as a pretreatment forosmotic dehydration of banana slices (Musa cavendishii) finish-dried by dehumidified air drying. Food and Bioprocess Technology, 7(5), 1281-1297.

Zhang, M., Tang, J., Mujumdar, A. S., \& Wang, S. (2006). Trends in microwave-related drying of fruits and vegetables. Trends in Food Science and Technology, 17(10), 524-534.

Zielinska, M., \& Markowski, M. (2010). Air drying characteristics and moisture diffusivity of carrots. Chemical Engineering and Processing, 49(2), 212-218.

Zielinska, M., \& Markowski, M. (2018). Effect of microwave-vacuum, ultrasonication, and freezing on mass transfer kinetics and diffusivity during osmotic dehydration of cranberries. Drying Technology, 36(10), 1158-1169.

Zielinska, M., Ropelewska, E., Xiao, H. W., Mujumdar, A. S., \& Law, C. L. (2019). Review of recent applications and research progress in hybrid and combined microwave-assisted drying of food products: quality properties. Critical Reviews in Food Science and Nutrition, 60(13), 2212-2264. https://doi.org/10.1080/10408398.2019.1632788.

Zielinska, M., Ropelewska, E., \& Zapotoczny, P. (2018). Effects of freezing and hot air drying on the physical, morphological and thermal properties of cranberries (Vaccinium macrocarpon). Food and Bioproducts Processing, 110, 40-49.

Zielinska, M., Sadowski, P., \& Blaszczak, W. (2016). Combined hot air convective drying and microwave vacuum drying of blueberries (Vaccinium corymbosum L.): Drying kinetics and quality characteristics. Drying Technology, 34(6), 665-684.

Zielinska, M., Sadowski, P., \& Blaszczak, W. (2015). Freezing/thawing and microwave assisted drying of blueberries (Vaccinium corymbosum $L$.). LWT- Food Science and Technology, 62(1-2), 555-563.

Zielinska, M., \& Zielinska, D. (2019). Effects of freezing, convective and microwave-vacuum drying on the content of bioactive compounds and color of cranberries. LWT-Food Science and Technology, 104, 202-209.

Publisher's Note Springer Nature remains neutral with regard to jurisdictional claims in published maps and institutional affiliations. 